\title{
Development and Operation of a Video Teleconsultation System Using Integrated Medical Equipment Gateway: a National Project for Workers in Underserved Areas
}

\author{
Hyun Sang Park ${ }^{1,2}$ (D) Kwang il Kim ${ }^{3}$. Jae Young Soh ${ }^{1} \cdot$ Young Ho Hyun ${ }^{1} \cdot$ Bang Eun Lee ${ }^{1} \cdot$ Jong Hwa Lee $^{1}$. \\ Jung Gwon Jo ${ }^{1} \cdot$ Han Chae Lee ${ }^{1} \cdot \mathrm{Hwa}_{\text {Sun } \mathrm{Kim}^{4}}$
}

Received: 28 February 2020 / Accepted: 25 September 2020 / Published online: 1 October 2020

(C) Springer Science+Business Media, LLC, part of Springer Nature 2020

\begin{abstract}
Worker health centers and health zones provide occupational healthcare services to workers in underserved areas of industrial health. Health zones cannot counsel workers on occupational disease prevention; worker health center personnel have to provide such services through in-person visits. Video teleconsultation can increase the accessibility of high-quality services to workers who visit health zones and improve professional personnel's efficiency. This study aimed to develop a system and an infrastructure that could facilitate video teleconsultation services between worker health centers and health zones, and analyze the services' operation status. A video teleconsultation process based on the role of local and remote institutions was designed. Based on the designed services, a web system supporting teleconsultation and an integrated gateway guaranteeing the interface with medical equipment in the web environment was developed. After analyzing the working environment, an infrastructure consisting of networks, video equipment, medical equipment, and servers necessary for teleconsultation was designed. Statistical results from the developed system and a satisfaction survey conducted by the Korea Occupational Safety and Health Agency were used to analyze the video teleconsultation services' operation status. A system, gateway, and hardware infrastructure within 21 worker health centers and 21 health zones has been operating this service since January 1, 2018. Over two years, the total number of teleconsultation service users was 4979, and the total number of questionnaire respondents was 1270 . The total number of service activities was 6388 and total satisfaction was rated as $4.58( \pm 0.59)$ out of 5. In this study, video teleconsultation services were evaluated as being very satisfactory. In particular, service accessibility and local medical personnel service were rated highly, demonstrating that the developed system and infrastructure were well designed according to the goals of the project.
\end{abstract}

Keywords Video Teleconsultation system $\cdot$ Underserved area $\cdot$ Integrated gateway $\cdot$ Worker health center $\cdot$ Health zone

This article is part of the topical collection on Patient Facing Systems

Hyun Sang Park

hspark@bit.kr

1 Digital Healthcare Department, BIT Computer Co Ltd, Seoul, Republic Of Korea

2 Department of Medical Informatics, Kyungpook National University, Daegu, Republic Of Korea

3 Finance Programs Department, Korea Occupational Safety \& Health Agency, Ulsan, Republic Of Korea

4 Elecmarvels Co Ltd, Daegu, Republic Of Korea

\section{Introduction}

Many people worldwide do not receive adequate treatment due to geographical, social, and cultural barriers [1-3]. People in medically underserved areas (e.g., farming and fishing villages) do not have access to high-quality services. Medical access is inhibited by insolvency, distance from tertiary care facilities, insufficient medical knowledge, limited traffic resources, and time constraints [4]. The key factor in addressing these barriers is the use of telemedicine, which enables medical personnel to access primary care sites through the use of information and communications technology (ICT) [5]. Telemedicine is the provision of medical knowledge or skills by remote medical personnel through ICT [6]. Telemedicine not only improves medical access for people in underserved areas, 
but can also reduce personal expenses and time needed to reach medical services in the city [7]. Telemedicine has been promoted as a means of addressing the imbalance in the distribution of medical resources [8], and many believe that telemedicine can significantly improve the supply of medical personnel [9].

The pandemic caused by coronavirus disease 2019 (COVID-19) [10], which first occurred in Wuhan, China in December 2019, is a threat to global health [11]. Due to the COVID-19 pandemic, medical care providers are currently focusing their attention on telemedicine, which avoids face-toface contact between doctors and patients, and allows patients to receive necessary treatment $[12,13]$. Telemedicine is recommended as a solution to COVID-19 [13] and makes it possible to provide high-quality treatment while decreasing the risk of infection by reducing contact between patients and medical personnel or between patients [14, 15]. The existing advantages of telemedicine [16], such as improved medical access and reduced costs, also apply to COVID-19. Before COVID-19, telemedicine was mainly used for elderly people or those with chronic diseases [17, 18] and primary care [19], but the actual use rate was low [20]. The reason for the low use rate was that patients prefer face-to-face consultation and were not aware that telemedicine was provided as an option [21]. However, the limitation of face-to-face consultations due to COVID-19 increased patient interest and preference for telemedicine [22], and the number of video teleconsultations rapidly increased [23]. Video teleconsultation has similar results to face-to-face consultation and can improve patient health and satisfaction and increase medical access $[24,25]$. As such, video teleconsultation has already attracted much interest in many countries as a part of national strategy [26-28].

The Republic of Korea has introduced telemedicine to increase access to medical care as well as reduce the burden of ever-increasing medical expenses. Under the agreement, the government and the medical community revised the Medical Service Act in March 2002 to enable telemedicine among medical personnel [29]. Since then, Korea has grown rapidly in the telemedicine market because of its strong IT infrastructure [30], but doctor-patient telemedicine has only been carried out through some pilot projects due to conflicting opinions (e.g., effectiveness, safety, allowable range, and major hospital tipping phenomenon) between the government and the medical community [31]. Permitted teleconsultation within the various categories of telemedicine requires that local medical personnel follow the behavior of remote medical personnel after having established facilities and equipment (e.g., medical equipment, video equipment, servers, and telecommunication networks) [29]. National and local governments have been conducting teleconsultation projects for people with limited access to traditional medical services due to distance or behavior [31]. They largely provided various telemedicine services to residents in medically underserved areas (e.g., island residents, military soldiers, seafarers, and prisoners of correctional facilities). However, workplaces with $<50$ workers in medical blind spots have also been included recently.

According to an analysis of workplace accidents [32] conducted by the Ministry of Employment and Labor in 2017, $81 \%$ of the total number of work injuries occurred in workplaces with $<50$ workers. Workplaces with $<50$ workers accounted for $98 \%$ of the total workplaces, and $58 \%$ of the total workers belonged to workplaces with $<50$ workers. Since workplaces with $<50$ workers are not obligated to appoint health officers under the Occupational Safety and Health Act [33], they are very vulnerable to occupational diseases and industrial accidents. Relative to the general public, the majority of workers are at an increased risk for health issues due to stress caused by heavy workloads and unhealthy lifestyles (e.g., lack of exercise and frequent drinking) [34]. Cerebral and cardiovascular diseases account for $35 \%$ of workers' deaths from occupational diseases, $68 \%$ of which occur in workplaces with $<50$ workers [32]. As the necessity of providing health promotion services for small-scale workplaces emerged, the government established worker health centers (WHCs) in 2011 [35]. WHCs are institutions that are set up in dense areas of small-scale workplaces (e.g., industrial parks) and provide services for the prevention of occupational diseases among workers. There are currently 21 WHCs in operation in Korea [36].

A WHC is comprised of professional personnel, such as those in the field of occupational environmental medicine, occupational nurses, industrial hygiene safety engineers, physical therapists, and counseling psychologists. They provide comprehensive occupational healthcare services including occupational disease prevention, cerebrovascular disease prevention, musculoskeletal disease prevention, workplace environment counseling, job stress prevention, lifestyle improvement, and post-care management. The WHCs are distributed throughout the country, but geographical and time limitations make it difficult for workers to use them. To address this problem, WHCs began operating health zones (HZs) in 2016 in industrial parks far from the jurisdiction; there are currently $21 \mathrm{HZs}$ in Korea [36]. An HZ is staffed by one or two industrial nurses and physical therapists. Every year, the number of users and counseling services provided within WHCs and HZs increase due to user satisfaction and professional improvement [36]. However, HZ staff cannot provide professional occupational healthcare services to visiting workers - these must be provided by the professional personnel of the WHC who visit the HZ. As a result, it is necessary to expand services to provide professional occupational healthcare to workers who visit HZs regardless of the time of day and to efficiently cooperate with the professional personnel of the WHCs. 
In telemedicine, video conferencing synchronizes the user's voice and video over two or more physically separated interagency networks [37]. Video teleconsultation not only includes the benefits of face-to-face consultation but also addresses the cost and inconvenience issues presented by geographical distances between service providers and users [38]. According to previous studies [25, 39-41], clinical consultation through video links is related to the high satisfaction of patients and doctors. The popularity of video teleconference has increased significantly in recent years [42], and most service providers have shifted from voice to video consultation [43]. As a result, the Korea Occupational Safety and Health Agency (KOSHA) has promoted a project to provide video teleconsultation services to workers who visit HZs. This study aimed to develop and operate a system and infrastructure that can facilitate video teleconsultation services between WHCs and HZs. We designed a video teleconsultation process suitable for WHCs and HZs and constructed a system and hardware in order to execute it. Additionally, we developed an integrated gateway for the interface between various medical equipment and systems in HZs. Finally, we used the statistical results of the developed system and of a satisfaction survey conducted by KOSHA to analyze the video teleconsultation services' current operational status.

\section{Methods}

\section{Service Design}

Occupational healthcare services for underserved areas have continued to expand, but the quality of services between WHC and HZ jurisdictions vary widely: HZs are less capable of counseling on occupational disease prevention and the dispatch of occupational environmental medicine professionals from a WHC to an $\mathrm{HZ}$ each time is a burden on internal personnel. It is necessary to establish a teleconsultation service using ICT to provide high-quality services to workers who visit HZs and to efficiently operate professional personnel in WHCs. Video teleconsultation often uses platforms designed for video conferencing (e.g., Facetime, Hangouts, and Skype), but this is not compatible with clinical workflows and routines [44].

This study designed a video teleconsultation process (Fig. 1) according to HZ (local) and WHC (remote) roles. The local institution selected video teleconsultation based on the decision of local medical personnel. If video teleconsultation was required, the local medical personnel registered the reception of information with the system and called the remote institution to connect the video conference. The remote institution provided video teleconsultation after accepting the video conference call. The remote medical personnel consulted with the worker based on their information transmitted through the system and the data of the real-time medical equipment passing through the integrated gateway. After the conclusion of the video teleconsultation, the local medical personnel completed the worker's occupational healthcare services. These processes have been designed in consultation with the advisory committee of the WHC to operate within the workflow and routine of each institution.

\section{System and Gateway Design}

The teleconsultation systems should support patient information sharing between local and remote institutions as well as reservation/reception, patient information management, patient health and counseling information management, and statistics - similar to a traditional healthcare system. Patient information can be shared by using international standards between heterogeneous systems to ensure interoperability, or by applying standardized systems to limited institutions. This study developed a standardized system for the integrated management of scattered data not only for teleconsultation but also for the efficient health management and data analysis of worker groups.

The system's work process and functions were designed based on the requirement analysis of KOSHA, WHCs, and HZs. The work process is divided into the registration of a visiting worker, reservation/reception, occupational health counseling, and completion; information sharing is allowed only to the WHC selected at the time of reception at the HZ. In other words, access control and authentication for personal information were applied by setting the scope of access to data in the system according to the user's organization and their assigned role. After compiling the functions of existing systems used by each institution, the necessary functions were selected through the user survey. Finally, the system's user interface was determined through a focus group interview with WHCs and HZs.

During a teleconsultation, the local institution must transmit patient data measured with medical equipment to the remote institution to assist the remote medical personnel's medical practice. Depending on the type of equipment, patient data includes not only simple numerical data such as blood pressure and blood sugar levels but also complex numerical data such as electrocardiogram results. In order to transmit these data, the local institution must be connected to an interface between the system and the medical equipment. However, most equipment can only interface via protocols and methods provided by each manufacturer. The more diverse the types of equipment, the more collision problems may arise due to different interface methods. In addition, web systems cannot communicate between browsers and medical equipment, so it is difficult to comply with the interface methods provided by the manufacturer. Therefore, this study developed an integrated gateway that can guarantee the interface of measured data from medical equipment in the web environment. The 


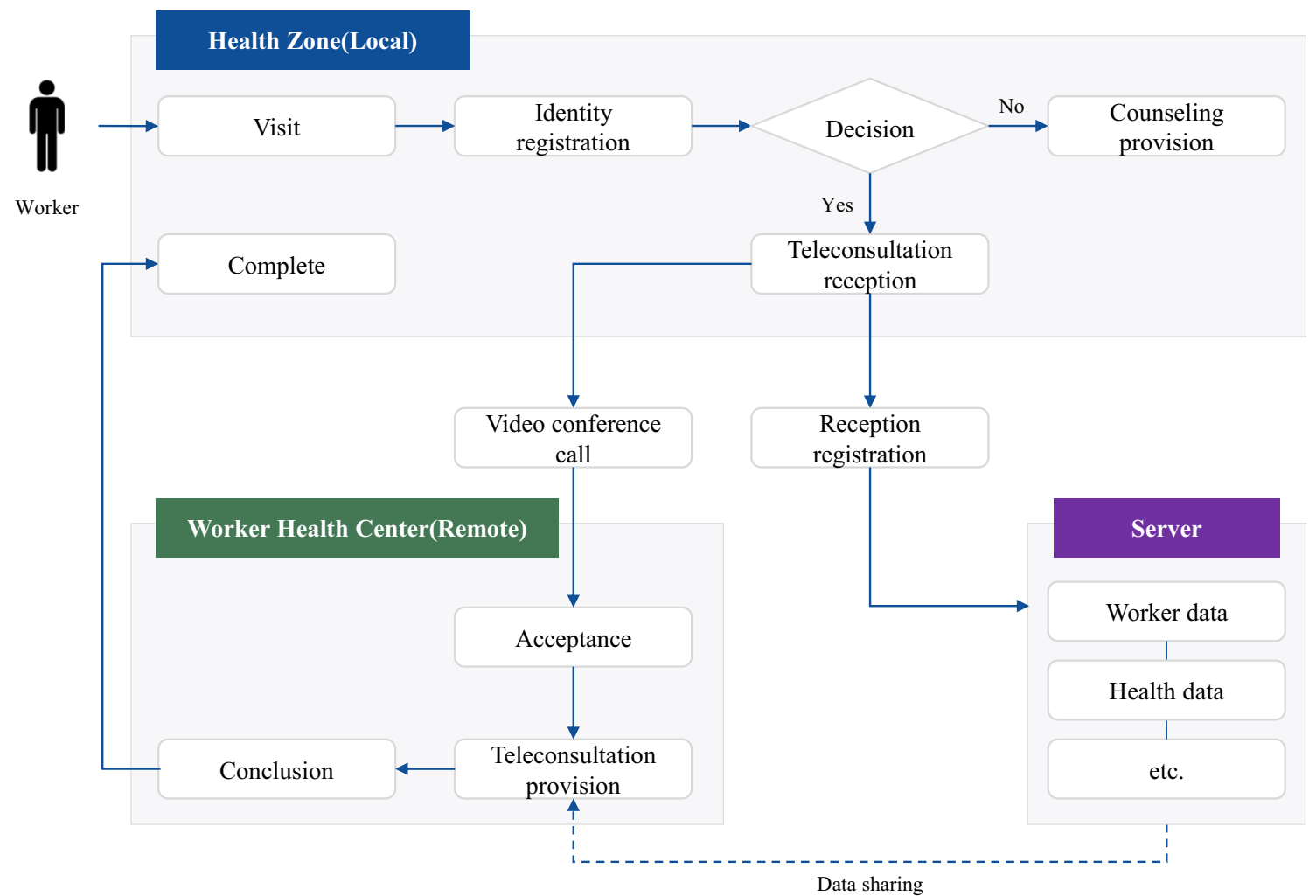

Fig. 1 Design of video teleconsultation process between worker health centers and health zones

integrated gateway was applied after designing a formalized protocol to unify the way in which measurement data were extracted from medical equipment in the HZs. These gateways allow local medical personnel to easily obtain medical equipment data and transmit them to remote institutions.

This study designed a process (Fig. 2) based on the integrated gateway between HZs (local) and WHCs (remote). The local medical personnel transmitted the measurement message to the gateway client via the web client. The gateway client that received the message attempted to connect with the medical equipment to receive the measured data and transmitted the value to the gateway server and the web server. The server stored the received message in the database or transmitted it to the connected remote gateway client. The remote gateway client delivered the measurements to the remote medical personnel via a web client. In this process, the gateway client parsed the packet received from the web client through a web socket, and the communication system between the medical equipment and the server transmitted and received the message through an abstraction-based formalized protocol. The data between the client and the server were sent securely by applying a Secure Sockets Layer (SSL), and the personal information in the packet was processed by applying ARIA256 and SHA256 to encrypt and decrypt the data. The gateway server deleted the temporarily stored data when sending a message to a remote gateway client.

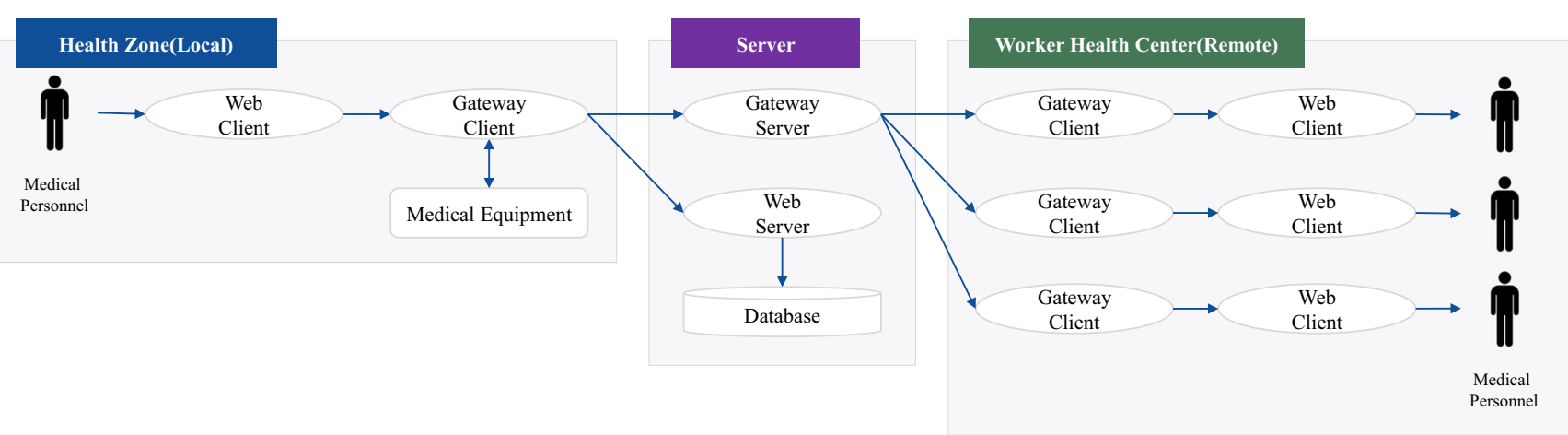

Fig. 2 Conceptual diagram of video teleconsultation process using integrated medical equipment gateway 


\section{Hardware Configuration}

Video teleconsultation offers many benefits to patients, but also entails ethical issues [45]. Accordingly, there are concerns regarding technology and clinical quality, privacy, safety, and responsibility [44, 46, 47]. Appropriate hardware infrastructure should be established within the facility to perform teleconsultation. This infrastructure must ensure the prevention of personal information leakage and security when using web systems and video teleconsultation, and all equipment must be reliable and secure. After analyzing the working environments of HZs and WHCs, this study designed an infrastructure consisting of a network, video, and medical equipment, and servers required for teleconsultation (Fig. 3). The networks at WHCs and HZs have configured switching hubs and VPN clients [48] so that they can connect to a VPN server [48]. These VPNs secure data in the infrastructure from the outside through functions such as address and router system privacy, data encryption, user authentication, and authority restrictions, and securely transmit personal information and video teleconsultation information between WHC and $\mathrm{HZ}$ through tunneling. Video and medical equipment vary depending on the roles of the local and remote institutions. The HZs deployed a rack-based video system [49] so that industrial nurses (local medical personnel) could request and provide video teleconsultation to the visiting workers. Next to the rack are a blood pressure meter [50], blood glucose meter [51], body composition meter [52], cholesterol meter [53], stress meter [54], thermometer [55], and medical scope [56]. In this way, the measured worker data could be transmitted to the remote institution via an integrated gateway. The WHCs deployed an integrated video camera [57] and a desktop for the occupational environmental medicine professionals (remote medical personnel) to perform the requested video teleconsultation from the HZ. Finally, the server consisted of a VPN server, web server, database server, and gateway server in the data center for additional network security and physical security.

\section{Data Collection and Analysis}

After receiving approval for research purposes from KOSHA, we used the statistical results of the developed system and the satisfaction survey data for the workers who visited the HZs. The statistical results used data from video teleconsultations conducted at $21 \mathrm{WHCs}$ and $21 \mathrm{HZs}$ for two years from January 1, 2018 to December 31, 2019. Frequency analysis was performed to analyze service users' general characteristics, the ratio of video teleconsultations to user and service activities overall, monthly activity trends, and the number of counseling reasons by type.

KOSHA conducts an annual satisfaction survey of workers who visited the WHCs and HZs in order to improve their business processes and evaluate institutions. This study used the HZs' satisfaction survey data, which are evaluated

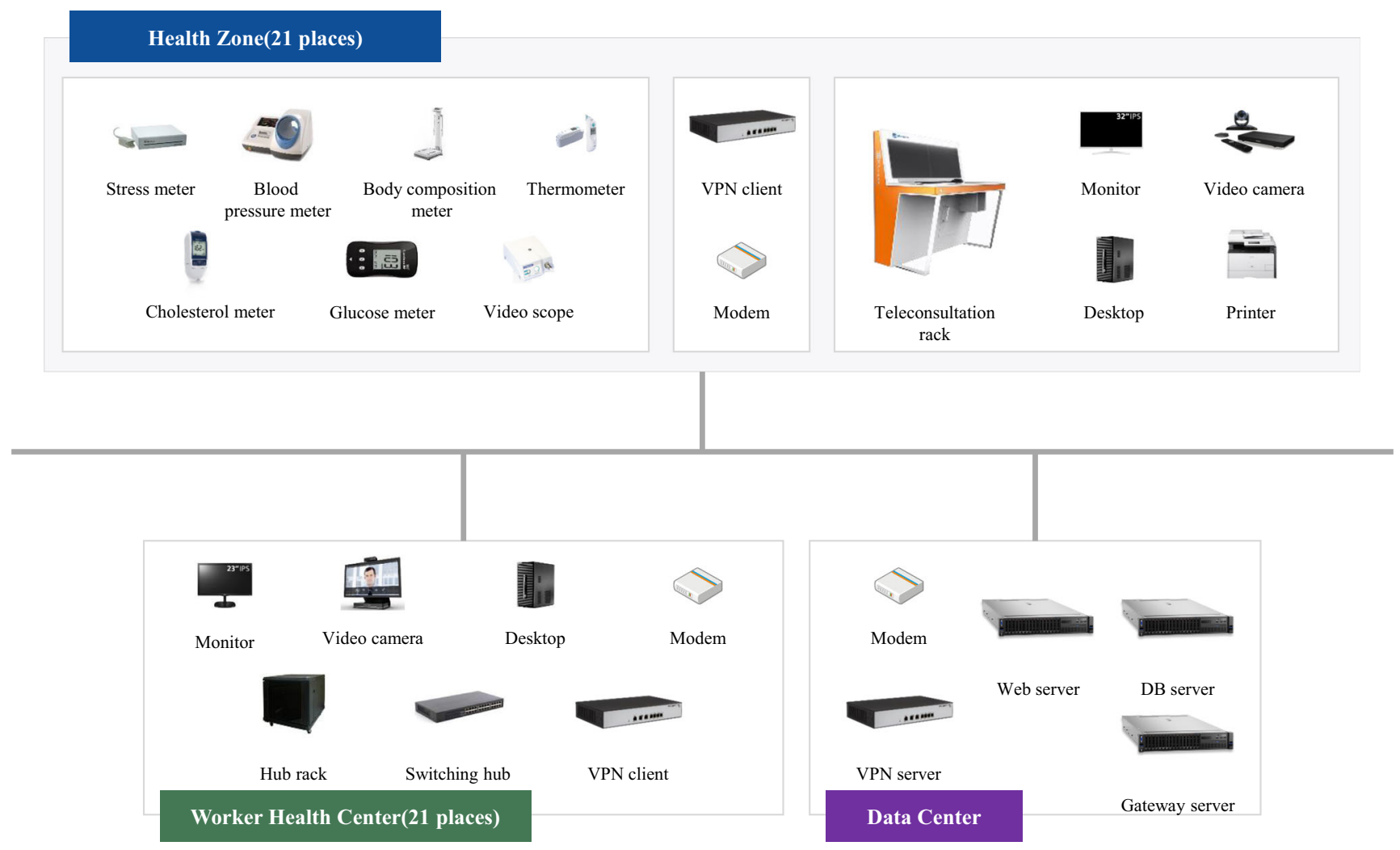

Fig. 3 Design of hardware architecture for video teleconsultation services 
regarding the video teleconsultation services. The satisfaction survey was conducted with workers who visited an HZ between January 1 and October 31, 2018 or January 1 and October 31,2019 . The survey was conducted with 30 workers at each $\mathrm{HZ}$ using a structured questionnaire-based telephone interview. We used a quota sampling method from the list of service users, and several investigators were employed to reduce inter-investigator deviations. The questionnaire consisted of 12 items about respondents' general characteristics and 11 items about service satisfaction (Table 1), each rated on a five-point Likert scale. The survey was conducted from November 19 to November 30, 2018 and from October 21 to November 15, 2019. Frequency analysis was performed to analyze respondents' general characteristics. Reliability analysis and exploratory factor analysis were performed to analyze the reliability and validity of the instrument. Means and standard deviations were calculated to summarize the data for each question. All analyses were performed using SPSS 25.0 (IBM Corp., Armonk, NY, USA).

\section{Results}

\section{Service Environment}

This study established a system, a gateway, and a hardware infrastructure in $21 \mathrm{WHCs}$ and $21 \mathrm{HZs}$. The hardware infrastructure construction took place from June 12 to July 7 , 2017, after which field testing and user education from November 20, 2017 to December 30, 2017. User education was provided to approximately 250 medical personnel and included instructions for system, gateway, medical equipment, and video equipment use. Then video teleconsultation practices were conducted according to virtual scenarios. The system started running the service on January 1, 2018. Our research ended on December 31, 2019. Within the HZs, the local medical personnel conducted video teleconsultations with workers at teleconsultation studios. The studio is an independent space within the HZ and is equipped with a system, video, and medical equipment. The local medical personnel implemented the teleconsultation system (left monitor) to share the reception and worker information while outputting the video image (right monitor) of the remote medical personnel (Fig. 4-A). The remote medical personnel consulted with the workers and local medical personnel (left monitor) while checking the shared worker information and measured data from medical equipment through the teleconsultation system (right monitor) (Fig. 4-B).

\section{Service Operation}

The total number of teleconsultation service users was 4979 . Service users' general characteristics are shown in Table 2. The sample consisted of more women $(55.3 \%, n=2754)$ than men $(44.7 \%, n=2225)$. Most service users were in their $50 \mathrm{~s}$ $(32.5 \%, n=1620)$, followed by those in their $40 \mathrm{~s}(22.4 \%, n=$ 1117), 30s $(16.1 \%, n=801)$, and $60 \mathrm{~s}(15.8 \%, n=785)$. Most workers' employers were service-based $(52.5 \%, n=2612)$, and $85.6 \%$ of workers were employed in workplaces with $<50$ workers. More workers were engaged in service-based occupations $(45.0 \%, n=2241)$ than in clerical $(27.5 \%, n=$ $1368)$ or production-based $(17.1 \%, n=853)$ occupations.

The operation status of the video teleconsultation services is shown in Fig. 5. Video teleconsultation users accounted for $36 \%(n=4979)$ of all workers $(n=13,824)$ who visited the
Table 1 Overview of questionnaire

\begin{tabular}{|c|c|c|}
\hline Category & Number & Item \\
\hline Accessibility & 1 & Is it easy to access the health zone? \\
\hline \multirow[t]{3}{*}{ Effectiveness } & 2 & Do you think video teleconsultation is better than face-to-face consultation? \\
\hline & 3 & $\begin{array}{l}\text { Do you feel less reluctant to receive video teleconsultation than to go to a } \\
\text { nearby hospital? }\end{array}$ \\
\hline & 4 & $\begin{array}{l}\text { Do you think video teleconsultation with experts in other fields besides } \\
\text { occupational environmental medicine is good? }\end{array}$ \\
\hline \multirow[t]{4}{*}{ Service level } & 5 & Do you think the length of time of video teleconsultation is appropriate? \\
\hline & 6 & Is the content of the video teleconsultation helpful? \\
\hline & 7 & $\begin{array}{l}\text { Are you satisfied with the content and level of the video teleconsultation } \\
\text { service provided by the worker health center staff? }\end{array}$ \\
\hline & 8 & $\begin{array}{l}\text { Are you satisfied with the content and level of the service provided by the } \\
\text { health zone staff? }\end{array}$ \\
\hline \multirow{2}{*}{$\begin{array}{l}\text { Equipment and } \\
\text { environment }\end{array}$} & 9 & Are you satisfied with the use of facilities and equipment in the health zone? \\
\hline & 10 & Are you satisfied with the internal environment of the health zone? \\
\hline Intention to return & 11 & $\begin{array}{l}\text { Do you intend to return to the health zone for continuous video } \\
\text { teleconsultation? }\end{array}$ \\
\hline
\end{tabular}


Fig. 4 The video teleconsultation setting: (a) a worker and occupational nurse in a health zone's teleconsultation studio and (b) an occupational

environmental medicine professional in the worker health center's clinic room

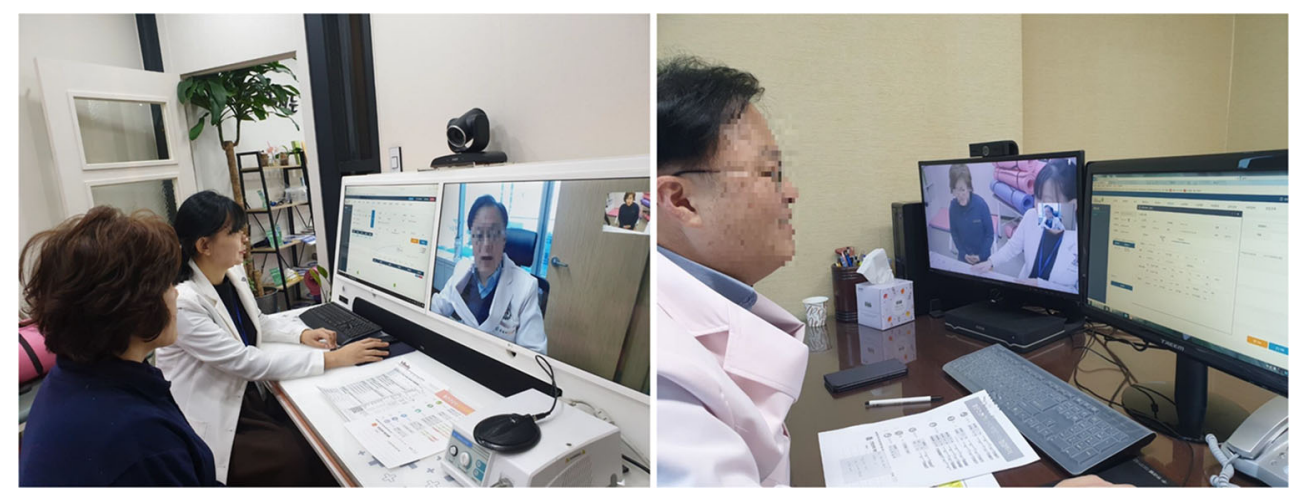

$\mathrm{HZs}$, and video teleconsultations accounted for $18 \%(n=$ $6388)$ of the HZ's service activities overall $(n=35,001)$. The most common reason for consultation was cerebrovascular disease $(52 \%, n=3300)$, followed by musculoskeletal disease, occupational disease, and job stress. The number of video teleconsultation activities per month showed a similar trend in 2018 and 2019 (Fig. 6). In 2018, engagement in video teleconsultation was highest in May $(14.9 \%, n=495)$ and lowest in December $(2.0 \%, n=68)$; in 2019, it was highest in June $(15.4 \%, n=471)$ and lowest in December $(1.6 \%, n=$ 50). The quarterly activity was highest in Q2 of both 2018 $(37.0 \%, n=1234)$ and $2019(38.0 \%, n=1163)$, followed by Q3, Q4, and Q1.

\section{Satisfaction Results}

The total number of questionnaire respondents was 1270 . Respondents' general characteristics are shown in Table 3. This study's sample included more men $(64.1 \%, n=814)$ than women $(35.9 \%, n=456)$. Most respondents were in their $50 \mathrm{~s}$ (27.8\%, $n=353)$, followed by those in their 40s $(23.5 \%, n=$ 298), 30s (19.1\%, $n=243)$, and 60s $(12.8 \%, n=163)$. The duration of employment in the workplace was most commonly $<1-5$ years $(40.9 \%, n=520)$, and the most frequent number of visits to an $\mathrm{HZ}$ was $1 \sim 2(74.3 \%, n=943)$.

Cronbach's $\alpha$ was 0.952 , which was considered very reliable. The Kaiser Meyer Elkin statistic was 0.952, the result of
Table 2 Teleconsultation service users' characteristics $(\mathrm{N}=4979)$

\begin{tabular}{llll}
\hline Measure & Items & Frequency & $(\%)$ \\
\hline Gender & Male & 2225 & 44.7 \\
Age (years) & Female & 2754 & 55.3 \\
& $<20$ & 18 & 0.4 \\
& $20-29$ & 492 & 9.9 \\
Type of employer & $30-39$ & 801 & 16.1 \\
& $40-49$ & 1117 & 22.4 \\
Type of occupation & $50-59$ & 1620 & 32.5 \\
& $60-69$ & 785 & 15.8 \\
& $\geq 70$ & 146 & 2.9 \\
& Manufacturing & 1370 & 27.5 \\
& Service-based & 2612 & 52.5 \\
& Other & 997 & 20.0 \\
Number of employees in the workplace & Production-based & 853 & 17.1 \\
& Clerical & 1368 & 27.5 \\
& Service-based & 2241 & 45.0 \\
& Other & 517 & 10.4 \\
& $<5$ & 1266 & 25.4
\end{tabular}


Proportion of service users

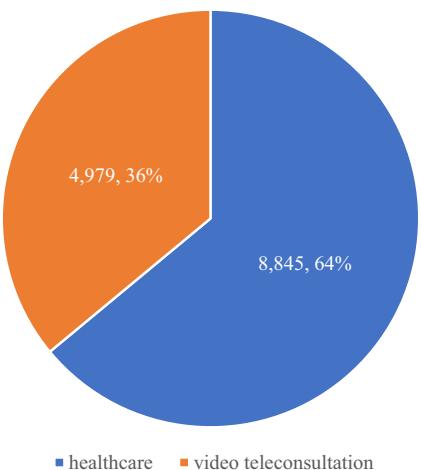

Proportion of service activity

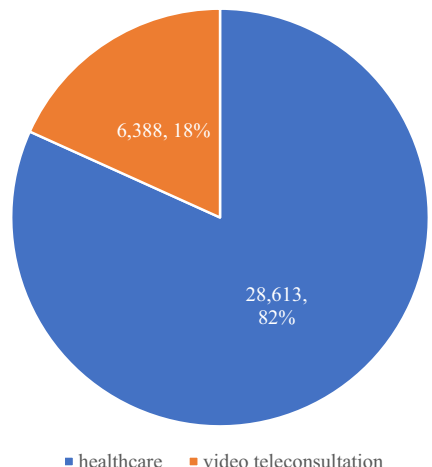

Proportion of consultation reason

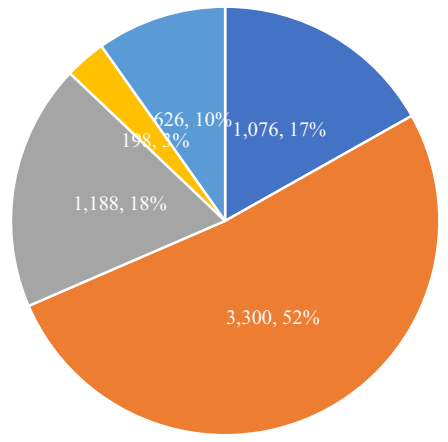

- occupational disease - cerebrovascular disease - musculoskeletal disease $=$ workplace environment - job stress

Fig. 5 Proportion of video teleconsultation services in health zones

Barlett's test was at $x^{2}(55)=9700.349(p<.001)$, and the factor analysis model was considered suitable. In addition, the cumulative variance was $65.76 \%$, and the explanatory power of the six factors was high. All factor loading values were above 0.4 , which demonstrated the validity of the overall instrument, and the analysis was performed without additional adjustment.

The satisfaction of the video teleconsultation service was $4.58( \pm 0.59)$ out of 5 , which was very satisfactory (Fig. 7). Of the 11 items, accessibility $(4.69 \pm 0.64)$ and local medical personnel service $(4.69 \pm 0.59)$ were rated relatively high, and preference $(4.43 \pm 0.86)$ was rated relatively low.

\section{Discussion}

The purpose of this study was to develop a system and an infrastructure that could facilitate a video teleconsultation service between WHCs and HZs to expand medical access for workers in underserved areas of industrial health. This study used the statistical results of the developed system and the results of a satisfaction survey conducted by KOSHA to analyze the current status of the operation of the video teleconsultation service. The main contents and results of the study are summarized as follows.

We designed a video teleconsultation service optimized for practice according to the roles of local and remote institutions. The WHCs and HZs have carried out various activities, such as occupational healthcare services for workers, on-site consultation services for the workplace, and cooperative systems establishment through networking among various institutions in the community [58]. Video teleconsultation was introduced to reduce the time and costs incurred by professional personnel of WHCs visiting HZs and to more easily provide highquality services to workers who visited the HZs. Previous studies [59-61] have emphasized the need for close collaboration between medical personnel and developers, as inappropriate systems can adversely affect telemedicine services
Fig. 6 Number of video

600 teleconsultation activities per month

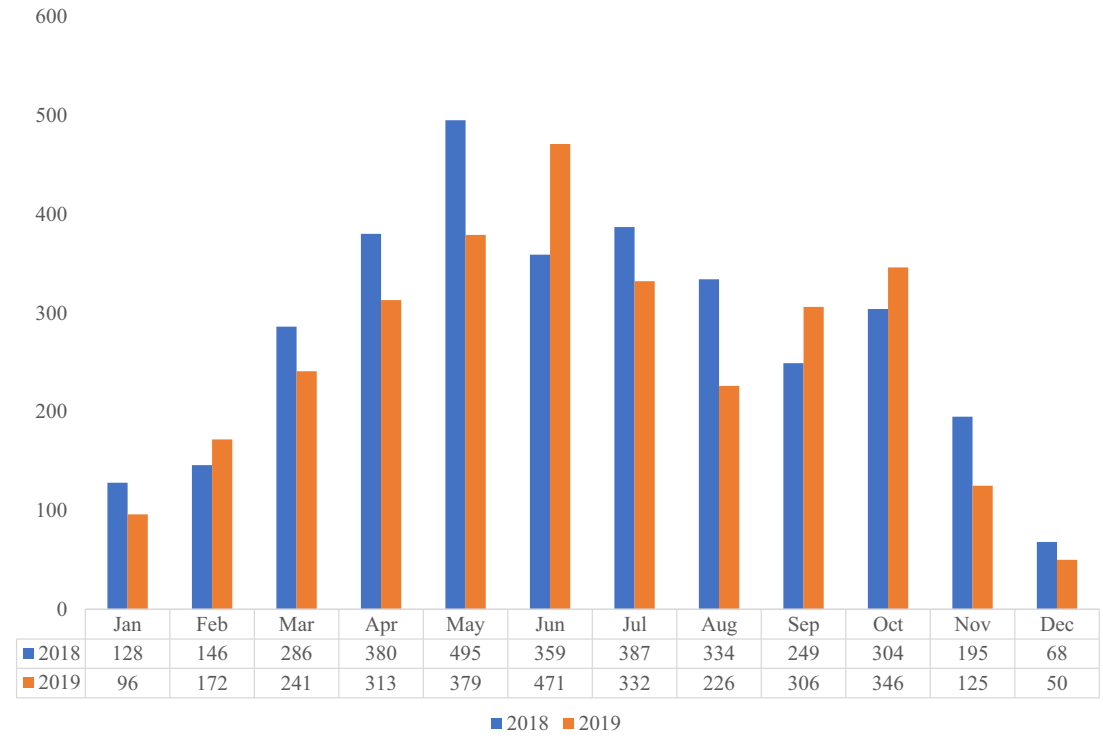


Table 3 Respondents' characteristics $(N=1270)$

\begin{tabular}{|c|c|c|c|}
\hline Measure & Items & Frequency & $(\%)$ \\
\hline \multirow[t]{2}{*}{ Gender } & Male & 814 & 64.1 \\
\hline & Female & 456 & 35.9 \\
\hline \multirow[t]{7}{*}{ Age (years) } & $<20$ & 8 & 0.6 \\
\hline & $20-29$ & 187 & 14.7 \\
\hline & $30-39$ & 243 & 19.1 \\
\hline & $40-49$ & 298 & 23.5 \\
\hline & $50-59$ & 353 & 27.8 \\
\hline & $60-69$ & 163 & 12.8 \\
\hline & $\geq 70$ & 18 & 1.4 \\
\hline \multirow[t]{3}{*}{ Type of employer } & Manufacturing & 335 & 26.4 \\
\hline & Service-based & 412 & 32.4 \\
\hline & Other & 523 & 41.2 \\
\hline \multirow[t]{4}{*}{ Type of occupation } & Production-based & 234 & 18.4 \\
\hline & Clerical & 431 & 33.9 \\
\hline & Service-based & 455 & 35.8 \\
\hline & Other & 150 & 11.8 \\
\hline \multirow[t]{6}{*}{ Number of employees in the workplace } & $<5$ & 250 & 19.7 \\
\hline & $5-9$ & 152 & 12.0 \\
\hline & $10-29$ & 304 & 23.9 \\
\hline & $30-49$ & 235 & 18.5 \\
\hline & $50-99$ & 106 & 8.3 \\
\hline & $\geq 100$ & 223 & 17.6 \\
\hline \multirow[t]{4}{*}{ Time in the workplace (years) } & $<1$ & 197 & 15.5 \\
\hline & $1-4$ & 520 & 40.9 \\
\hline & $5-9$ & 230 & 18.1 \\
\hline & $\geq 10$ & 323 & 24.4 \\
\hline \multirow[t]{4}{*}{ Number of visits to an $\mathrm{HZ}$} & $1 \sim 2$ & 943 & 74.3 \\
\hline & $3-5$ & 206 & 16.2 \\
\hline & $6-9$ & 45 & 3.5 \\
\hline & $\geq 10$ & 76 & 6.0 \\
\hline
\end{tabular}

Fig. 7 Results of video teleconsultation services satisfaction survey

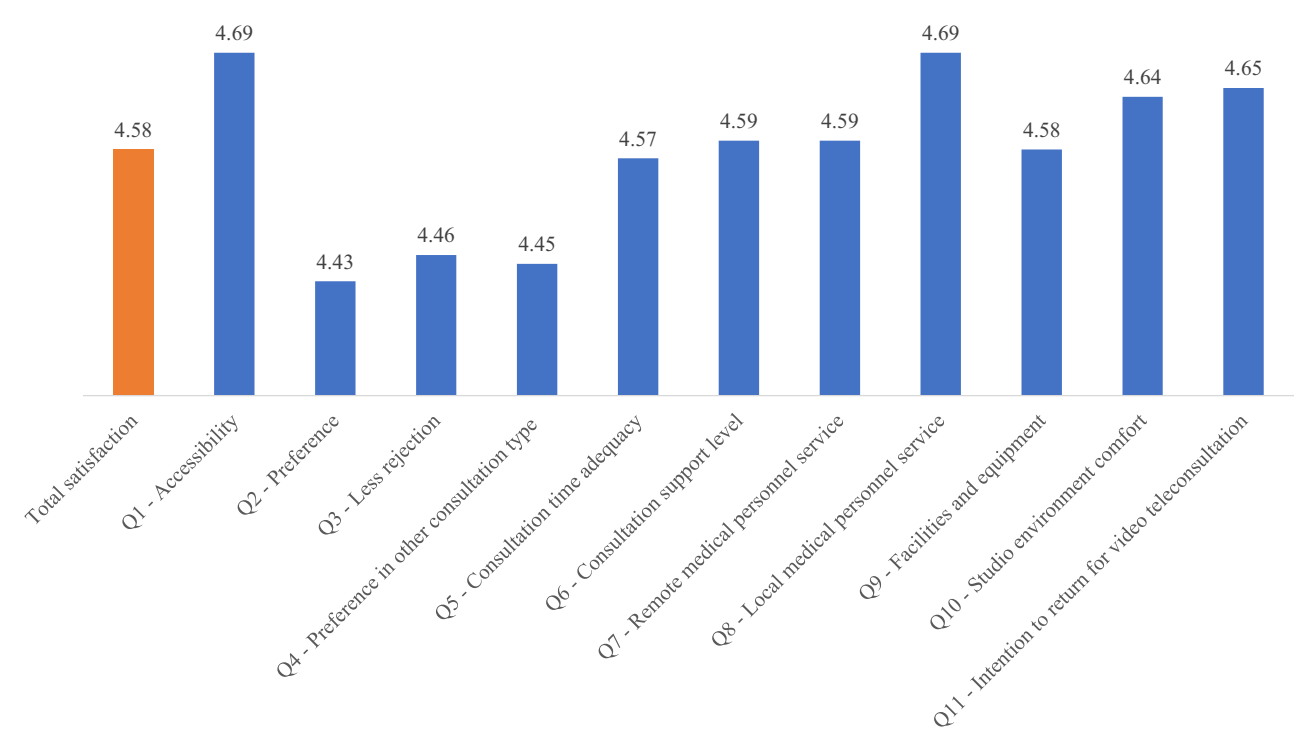


[62-65]. Therefore, this study designed the reception and callbased process considering the role of each institution and medical personnel, and revised the process of existing visits through meetings with the advisory committee of the WHC organized by the KOSHA.

Based on the designed service, we developed a system and an integrated gateway that supports teleconsultation. WHCs and HZs have been set up nationwide with the purpose as providing occupational healthcare services to workers, but the operating direction depends on the type of workplace or type of occupation to be managed within the installed area. Because of these effects, each institution has used different systems. The use of such a system inhibits the integration and management of the vast amount of meaningful data due to the lack of data standardization and distributed databases, especially the sharing of worker information for teleconsultation. Therefore, this study developed a standardized system that can manage worker information as well as the designed video teleconsultation service. The developed system allows remote medical personnel to access information on workers who visited the local institution during video teleconsultation, and the local medical personnel can check the records made by the remote medical personnel and take follow-up measures. In particular, the system can transmit and receive data measured on medical equipment via an interface with the developed integrated gateway as a web client role. The integrated gateway developed in this study communicates with the web client, gateway client, and server via a web socket, so it is possible to acquire medical equipment data in the web environment. The integrated gateway serializes and deserializes data from medical equipment to standardized protocols, regardless of the communication method (e.g., socket communication using TCP/IP, serial communication using RS-232, manufacturer API, or program) or equipment type (e.g., blood pressure meter, blood glucose meter, and body composition meter). Thanks to this integrated gateway, local medical personnel at an HZ can easily send workers' data measured from various medical equipment to a WHC, and remote medical personnel at the WHC can check the data received during video teleconsultation in real-time.

We established a hardware infrastructure at 21 WHCs and $21 \mathrm{HZs}$ that can operate video teleconsultation services. Medical Service Act requires that facilities and equipment be established in order to perform or receive telemedicine. In other words, the institution should have a telemedicine studio and equipment such as a terminal, a server, and an information communication network capable of transmitting and receiving data and images. Of these, medical equipment should be located at a local institution and transmit the patient's data measured from the equipment to support remote medical personnel in providing medical knowledge and skills to local medical personnel. Therefore, this study established teleconsultation studios in the HZs and arranged for various medical equipment together with the video system. According to a previous study [66], medical personnel decide to quit when they cannot move to another space or make a suitable space for telemedicine. A solution to this problem has been to provide desktop-based services so that medical personnel can perform telemedicine directly from their office [67]. Therefore, this study installed an integrated video camera and desktop in occupational environmental medicine professionals' offices at the WHC. Finally, in order to solve the privacy and security problems that can occur during telemedicine [68], we configured the VPN to ensure the confidentiality of the developed system and video equipment. In addition, an SSL channel was used for data transmission.

Using the quantitative data, we analyzed the operation status and satisfaction of the video teleconsultation service. According to system records, 4979 (36\%) of the 13,824 workers used video teleconsultation services. Engagement in the service activity in $2019(n=3057)$ was slightly less than in $2018(n=3331)$, but the monthly and quarterly patterns were the same. The total satisfaction of the video teleconsultation service was evaluated as very high at $4.58( \pm 0.59)$, and all 11 items were evaluated at 4.43 or higher. The high evaluation of accessibility $(4.69 \pm 0.64)$ and local medical personnel service $(4.69 \pm 0.59)$ due to video teleconsultation indicate that the project worked well based in its goals. This study solved the technical and operational problems encountered by previous studies for smooth service operation and high satisfaction. The limitations of performing physical examinations [69] during video teleconsultation were measured and transmitted through various medical equipment and integrated gateway. In addition, local medical personnel supported workers' physical examination measurements to ensure that the tests were performed correctly [70]. A previous study [71] demonstrated that patients are less satisfied with video teleconsultation if the image and audio quality are poor, and appropriate lighting and zoom cameras are needed for proper diagnosis and decisionmaking by medical personnel [72]. Therefore, this study deployed high-resolution video equipment and medical scopes in the studio, and network connectivity was guaranteed through an independent information communication network. The lack of education and support for medical personnel and patients is mentioned as a barrier to the use of video teleconsultation [73, 74], and education on video teleconsultation is necessary to provide quality services $[69,75]$. We visited each institution to provide user education for medical personnel and local medical personnel who completed the education assisted workers during video teleconsultation.

This study is the first to analyze system development and services' operation status for teleconsultation projects in occupational health in Korea. Unlike advanced countries where telemedicine has been legalized, Korea has been conducting telemedicine research only to a limited extent. Most studies deal with the legal and institutional regulations on 
telemedicine and the results of doctor-patient telemedicine pilot projects, and very few focus on the introduction and results of teleconsultation projects already in operation. This study is meaningful as a report on the development and operation status of a successful video teleconsultation system as a part of national occupational health projects. However, it was subject to some limitations. First, this study utilized the results of the satisfaction survey conducted for institutional evaluation, so the data analysis method was limited. Workers' responses were analyzed to compare the mean and standard deviation for each question through descriptive statistics. To derive more generalized research results, hypothesis testing will be necessary through data collection and analysis based on the research model. Second, this study could not confirm the effectiveness of the video teleconsultation service. Among the benefits of telemedicine, the improvement of access and satisfaction of demand could be confirmed through the satisfaction survey, but cost-effectiveness and clinical effectiveness could not be confirmed. WHCs and HZs are limited in cost-effectiveness analysis because they provide free services to the government to enhance public health. In addition, telemedicine among medical personnel is performed for consultation with remote medical personnel, and therefore is not suitable for the analysis of clinical effectiveness (e.g., experimental-control group or pre-post comparison) as doctor-patient telemedicine is. However, a previous study [25] indicated that there was limited evidence that video teleconsultation results in changes in patients' health outcomes. This is because telemedicine differs from the existing face-to-face consultation in the procedure and methods (e.g., collection, transmission, and analysis of patient information) of determining treatment or disease management, but the use of the existing treatment method is the same [76]. Finally, telemedicine is currently in the introduction review stage in Korea, and there is a lack of scholarly debate.

Korea has been amending the Medical Service Act since 2010 for doctor-patient telemedicine, but it remains stagnant. The government has been conducting various types of pilot projects since 2014 to demonstrate the effectiveness and safety of telemedicine. Through pilot projects, positive results were obtained for the service users' satisfaction and reliability. However, telemedicine services are not commercialized because it is difficult to reach consensus among various stakeholders on issues such as the lack of adequate compensation, fee schedule for new services, and responsibility attribution in case of an accident [30]. Telemedicine is therefore expected to grow slowly due to barriers such as policies, licensing issues, lack of standards, confidentiality, and accountability concerns [77-82]. The sudden outbreak of COVID-19 caused a major change in the Korean medical community. The Ministry of Health and Welfare temporarily allowed telemedicine (telephone consultation, phone prescription, proxy prescription, video treatment) from February 22, 2020 [83] to ensure the public's safety during the COVID-19 pandemic and to protect medical institutions and medical personnel from infectious sources. Telemedicine has been controversial, even before COVID-19, and has led to considerable confusion (lack of preparation for processes, infrastructure, and principles) even after temporary approval [84]. In contrast, countries that previously allowed telemedicine are expanding telemedicine after COVID-19. The US Department of Health \& Human Services temporarily relaxed the Health Insurance Portability and Accountability Act (HIPAA) regulations applied in telemedicine, allowing FaceTime and Skype to be used for telemedicine [85] and service providers were able to provide medical services by only listening to audio. The UK's National Health Service (NHS) recommended replacing primary care with telemedicine [86]. Currently, the number of cases employing telemedicine are increasing, and Scotland has observed an increase of over 1000 times in the last two weeks prior to this writing [87]. Japan allowed the first treatment to be performed through telemedicine, expanded the range of target diseases, and even allowed delivery of medicines [88].

In preparation for the prolonged period of the COVID-19 pandemic, Korea is seeking ways to incorporate telemedicine into regular medical services. KOSHA is reviewing video teleconsultation and tele-occupational health services using a personal health record (PHR) app for workers [89], and we are preparing a mobile service based on the established video teleconsultation infrastructure. Therefore, future studies will research factors to be considered in the introduction and expansion of mobile-based video teleconsultation services. In addition, we will conduct research analyzing workers' and medical personnel's satisfaction with mobile service, as well as the usage logs of workers collected through service operation.

Acknowledgments This study was conducted as part of the Korea Occupational Safety \& Health Agency's $2017 \sim 2019$ worker health center and health zone infrastructure construction project (contract number: 2017050AA2700, 2018050609E-00, 21193080000).

We would like to thank the Korea Occupational Safety \& Health Agency for approving the use of the data.

\section{Compliance with ethical standards}

Conflict of interest The authors declare that they have no conflict of interest.

Ethical approval This article does not contain any studies with human participants performed by any of the authors.

\section{References}

1. Chan, L., Hart, L. G., and Goodman, D. C., Geographic access to health care for rural Medicare beneficiaries. J Rural Health 22(2): 140-146, 2006. 
2. Fan, T., Koro, C. E., Fedder, D. O., and Bowlin, S. J., Ethnic disparities and trends in glycemic control among adults with type 2 diabetes in the U.S. from 1988 to 2002. Diabetes Care 29(8): 1924-1925, 2006.

3. Martens, P. J., Martin, B. D., O’Neil, J. D., and MacKinnon, M., Diabetes and adverse outcomes in a First Nations population: associations with healthcare access, and socioeconomic and geographical factors. Can J Diabetes 31(3):223-232, 2007.

4. Lasser, K. E., Himmelstein, D. U., and Woolhandler, S., Access to care, health status, and health disparities in the United States and Canada: results of a cross-national population-based survey. Am J Public Health 96(7):1300-1307, 2006.

5. Daniel, H., Sulmasy, L. S., and Delong, D. M., Health and Public Policy Committee of the American College of Physicians. Policy recommendations to guide the use of Telemedicine in primary care settings: an American College of Physicians position paper. Ann Intern Med 163(10):787-789, 2015.

6. Lustig T. A., The role of telehealth in an evolving health care environment: workshop summary. Washington (DC): National Academies Press, 2012.

7. Speyer, R., Denman, D., Wilkes-Gillan, S., Chen, Y. W., Bogaardt, H., Kim, J. H., Heckathorn, D. E., and Cordier, R., Effects of telehealth by allied health professionals and nurses in rural and remote areas: a systematic review and meta-analysis. $J$ Rehabil Med 50(3):225-235, 2018.

8. Institute of Medicine. Quality through collaboration: The future of rural health care. Washington (DC): National Academies Press, 2005.

9. Hjelm, N. M., Benefits and drawbacks of telemedicine. J Telemed Telecare 11(2):60-70, 2005.

10. Velavan, T. P., and Meyer, C. G., The COVID-19 epidemic. Trop Med Int Health 25(3):278-280, 2020

11. Wang, C., Horby, P. W., Hayden, F. G., and Gao, G. F., A novel coronavirus outbreak of global health concern. Lancet 395:470473, 2020.

12. Greenhalgh, T., Wherton, J., Shaw, S., and Morrison, C., Video consultations for covid-19. BMJ 368:m998, 2020.

13. Hollander, J. E., and Carr, B. G., Virtually perfect? Telemedicine for COVID-19. N Engl J Med 382:1679-1681, 2020.

14. Khairat, S., Meng, C., Xu, Y., Edson, B., and Gianforcaro, R., Interpreting COVID-19 and virtual care trends: Cohort study. JMIR Public Health Surveill 6:e18811, 2020.

15. Rockwell, K. L., and Gilroy, A. S., Incorporating telemedicine as part of COVID-19 outbreak response systems. Am J Manag Care 26:147-148, 2020.

16. Paquette, S., and Lin, J. C., Outpatient telemedicine program in vascular surgery reduces patient travel time, cost, and environmental pollutant emissions. Ann Vasc Surg 59:167e72, 2019.

17. Bertoncello, C., Colucci, M., Baldovin, T., Buja, A., and Baldo, V., How does it work? Factors involved in telemedicine homeinterventions effectiveness: A review of reviews. PLoS ONE 13(11):e0207332, 2018

18. Mallow, J. A., Petitte, T., Narsavage, G., Barnes, E., Theeke, E., Mallow, B. K., and Theeke, L. A., The use of video conferencing for persons with chronic conditions: A systematic review. E-Health Telecommun Syst Netw 5(2):39-56, 2016.

19. Peters, L., Greenfield, G., Majeed, A., and Hayhoe, B., The impact of private online video consulting in primary care. $J$ R Soc Med 111(5):162-166, 2018.

20. Barnett, M. L., Ray, K. N., Souza, J., and Mehrotra, A., Trends in Telemedicine Use in a Large Commercially Insured Population, 2005-2017. JAMA 320(20):2147-2149, 2018.

21. American Well. Telehealth Index: 2019 Consumer Survey. https:// static.americanwell.com/app/uploads/2019/07/American-WellTelehealth-Index-2019-Consumer-Survey-eBook2.pdf Accessed September 12, 2020
22. Evidation. COVID-19 Pulse: Delivering regular insights on the pandemic from a $150,000+$ person connected cohort. https:// evidation.com/news/covid-19-pulse-first-data-evidation/ Accessed September 12, 2020.

23. Phadke, N. A., Del Carmen, M. G., Goldstein, S. A., Vagle, J., Hidrue, M. K., Botti, E. S., and Wasfy, J. H., Trends in ambulatory electronic consultations during the COVID-19 pandemic. J Gen Intern Med:1-3, 2020.

24. Flodgren, G., Rachas, A., Farmer, A. J., and Inzitari, M., Interactive telemedicine: Effects on professional practice and health care outcomes. Cochrane Database Syst Rev 9:CD002098, 2015.

25. Ignatowicz, A., Atherton, H., Bernstein, C. J., Bryce, C., Court, R., Sturt, J., and Griffiths, F., Internet videoconferencing for patientclinician consultations in long-term conditions: A review of reviews and applications in line with guidelines and recommendations. Digit Health 5:2055207619845831, 2019.

26. Scottish Government. Scotland's digital health and care strategy: enabling, connecting and empowering. https://www.gov.scot/ publications/scotlands-digital-health-care-strategy-enablingconnecting-empowering/ Accessed September 12, 2020.

27. NHS England. NHS long term plan. https://www.england.nhs.uk/ long-term-plan/ Accessed September 12, 2020.

28. Australian Government. Safe, seamless and secure: Australia's national digital health strategy. https://conversation.digitalhealth.gov. au/sites/default/files/adha-strategy-doc-2ndaug_0_1.pdf Accessed September 12, 2020.

29. Korea Legislation Research Institute. Article 34 of the Medical Service Act. https://elaw.klri.re.kr/eng mobile/ganadaDetail.do? hseq=40970\& type $=$ abc \&key=MEDICAL \% 20SERVICE \% 20ACT\&param=M Accessed February 27, 2020.

30. Kim, H. S., Kim, H., Lee, S., Lee, K. H., and Kim, J. H., Current clinical status of telehealth in Korea: categories, scientific basis, and obstacles. Healthc Inform Res 21(4):244-250, 2015.

31. Oh, J. Y., Park, Y. T., Jo, E. C., and Kim S. M., Current status and progress of telemedicine in Korea and other countries. Healthc Inform Res 21(4):239-243, 2015.

32. Korea Ministry of Employment and Labor. Analysis of industrial accident situation, 2017. Sejong: MOEL Press, 2018.

33. Korea Legislation Research Institute. Article 15 and 16 of the Occupational Safety and Health Act. https:/elaw.klri.re.kr/eng service/lawView.do?hseq=43289\&lang=ENG Accessed February 27, 2020.

34. Kim, N. J., Relation between employees' life patterns and health conditions. Korean J Health Edu Promot 24(2):63-75, 2007.

35. Nam, K. C., Park, J. S., Koh, J. W., Kim, J. S., Park, J. T., Kim, H. J., Chung, J. J., Kim, J. Y., and Kim, D. S., An assessment of the needs and the affecting factors for small scale enterprise worker's health centers. Korean J Occup Environ Med 23(4):407-419, 2011.

36. Korea Ministry of Employment and Labor. Performance of the workers' health center and future operation directions, 2018. Sejong: MOEL Press, 2018.

37. Singh G., Secure video conferencing for web based security surveillance system. Master Thesis, Indian Institute of Technology, India, 2006.

38. Fatehi, F., Gray, L. C., Russell, A. W., and Paul, S. K., Validity study of video teleconsultation for the management of diabetes: a pilot randomized controlled trial. Diabetes Technol Ther 17(10): 717-725, 2015.

39. Armfield, N. R., Bradford, M., and Bradford, N. K., The clinical use of Skype - for which patients, ith which problems and in which settings? A snapshot review of the literature. Int J Med Inform 84(10):737-742, 2015.

40. Backhaus, A., Agha, Z., Maglione, M. L.,Repp, A., Ross, B., Zuest, D., Rice-Thorp, N. M., Lohr, J., and Thorp, S. R., Videoconferencing psychotherapy: a systematic review. Psychol Serv 9(2):111-131, 2012. 
41. Abimbola, S., Keelan, S., Everett, M., Casburn, Kim., Mitchell, M., Burchfield, K., and Martiniuk, A., The medium, the message and the measure: a theory-driven review on the value of telehealth as a patient-facing digital health innovation. Health Econ Rev 9(1):21, 2019.

42. Fatehi, F., Armfield, N. R., Dimitrijevic, M., and Gray, L. C., Clinical applications of videoconferencing: a scoping review of the literature for the period 2002-2012. J Telemed Telecare 20(7):377-383, 2014.

43. Clay-Williams, R., Baysari, M., Taylor, N., Zalitis, D., Georgiou, A., Robinson, M., Braithwaite, J., and Westbrook, J., Service provider perceptions of transitioning from audio to video capability in a telehealth system: a qualitative evaluation. BMC Health Serv Res 17(1):558, 2017.

44. Shaw, S., Wherton, J., Vijayaraghavan, S., Morris, J., Bhattacharya, S., Hanson, P., Richards, D. C., Ramoutar, S., Collard, A., Hodkinson, I., and Greenhalgh, T., Advantages and limitations of virtual online consultations in a NHS acute trust: the VOCAL mixed-methods study. NIHR Journals Library 6(21), 2018.

45. Chaet, D., Clearfield, R., Sabin, J. E., Skimming, K., and Council on Ethical and Judicial Affairs American Medical Association, Ethical practice in Telehealth and Telemedicine. J Gen Intern Med 32(10):1136-1140, 2017.

46. Donaghy, E., Atherton, H., Hammersley, V., McNeilly, H., Bikker, A., Robbins, L., Campbell, J., and McKinstry, B., Acceptability, benefits, and challenges of video consulting: a qualitative study in primary care. Br J Gen Pract 69(686):e586-e594, 2019.

47. Hall, J. L., and McGraw, D., For telehealth to succeed, privacy and security risks must be identified and addressed. Health Aff (Millwood) 33(2):216-221, 2014.

48. AXGATE. AXGATE series' next generation firewall. http://www. axgate.com/eng/?page_id=3909 Accessed February 27, 2020.

49. AVAYA. Avaya IXTM Room System XT4300. https://support. avaya.com/products/P1605/avaya-ix-room-system-xt4300 Accessed February 27, 2020.

50. InBody. Clinically validated blood pressure monitor BPBIO 320 S. https://inbodyusa.com/products/bpbio-320s/ Accessed February 27,2020

51. SD BIOSENSOR. STANDARD ${ }^{\mathrm{TM}}$ GlucoNavii GDH. http:// sdbiosensor.com/xe/product/2453 Accessed February 27, 2020.

52. InBody. InBody 570. https://inbodyusa.com/products/inbody570/ Accessed February 27, 2020.

53. SD BIOSENSOR. STANDARD ${ }^{\mathrm{TM}}$ LipidoCar. http://sdbiosensor. com/xe/product/2601 Accessed February 27, 2020.

54. MEDICORE. Max Pulse. http://medi-core.co.kr/en/hrv/max pulse. html Accessed February 27, 2020.

55. BRAUN. ThermoScan ${ }^{\circledR} 5$ - IRT6020. https://www.brauntherms. com/thermometer/thermoscan-5-ear-thermometer-irt6020/ Accessed February 27, 2020.

56. SOMETECH. Medical vision system. http://www.sometech.com/ eng/product/product.html?code $=003001$ Accessed February 27, 2020.

57. AVAYA. Avaya IX ${ }^{\mathrm{TM}}$ Executive XTE240. https://support.avaya. com/products/P1455/avaya-ix-executive-xte240 Accessed February 27, 2020.

58. Kim, J. S., Kim, D. S., Gil, H. J., Park, Y. S., Sin, H. H., and Park, J. T., Significance and prospect of workers health center. $J$ Korean Med Assoc 57(2):159-166, 2014.

59. Kim, H. S., Choi, W., Baek E. K, Kim, Y. A., Yang, S. J., Choi, I. Y., Yoon, K. H., and Cho, J. H., Efficacy of the smartphone-based glucose management application stratified by user satisfaction. Diabetes Metab J 38(3):204-210, 2014.

60. Ryan, D., Price, D., Musgrave, S. D., Malhotra, S., Lee, A. J., Ayansina, D., Sheikh, A., Tarassenko, L., Pagliari, C., Pinnock, H., Clinical and cost effectiveness of mobile phone supported self monitoring of asthma: multicentre randomised controlled trial. $B M J$ 344:e1756, 2012.

61. Liu, W. T., Huang, C. D., Wang, C. H., Lee, K. Y., Lin, S. M., and Kuo, H. P., A mobile telephone-based interactive self-care system improves asthma control. Eur Respir J 37(2):310-317, 2011.

62. Kim, H. S., Lee, K. H., Kim, H., and Kim, J. H., Using mobile phones in healthcare management for the elderly. Maturitas 79(4):381-388, 2014.

63. Yoo, H. J., Park, M. S., Kim, T. N., Yang, S. J., Cho, G. J., Hwang, T. G., Baik, S. H., Choi, D. S., Park, G. H., and Choi, K. M., A ubiquitous chronic disease care system using cellular phones and the internet. Diabet Med 26(6):628-635, 2009.

64. Park, M. J., Kim, H. S., and Kim, K. S., Cellular phone and Internetbased individual intervention on blood pressure and obesity in obese patients with hypertension. Int J Med Inform 78(10):704710,2009

65. Lim, S., Kim, S. Y., Kim, J. I., Kwon, M. K., Min, S. J., Yoo, S. Y., Kang, S. M., Kim, H. I., Jung, H. S., Park, K. S., Ryu, J. O., Shin, H., and Jang, H. C., A survey on ubiquitous healthcare service demand among diabetic patients. Diabetes Metab J 35(1):50-57, 2011.

66. Seto, E., Smith, D., Jacques, M., and Morita, P. P., Opportunities and challenges of telehealth in remote communities: case study of the yukon telehealth system. JMIR Med Inform 7(4):e11353, 2019.

67. Radhakrishnan, K., Xie, B., and Jacelon, C. S., Unsustainable home telehealth: a Texas qualitative study. Gerontologist 56(5):830-840, 2016.

68. Mat Kiah, M. L., Al-Bakri, S. H., Zaidan, A. A., Zaidan, B. B., and Hussain, M., Design and develop a video conferencing framework for real-time telemedicine applications using secure group-based communication architecture. J Med Syst 38(10):133, 2014.

69. Jiménez-Rodríguez, D., Santillán García, A., Montoro Robles, J., Rodríguez Salvador, M., Muñoz Ronda, F. J., and Arrogante, O., Increase in Video Consultations During the COVID-19 Pandemic: Healthcare Professionals' Perceptions about Their Implementation and Adequate Management. Int J Environ Res Public Health 17(14):5112, 2020.

70. BJGP Life. Video Consultations: A Guide for Practice. https:// bjgplife.com/2020/03/18/videoconsultations-guide-for-practice/ Accessed September 12, 2020.

71. Cargill, A., and Watson, A. R., Telecare support for patients undergoing chronic peritoneal dialysis. Perit Dial Int 23(1):91-94, 2003.

72. Coombes, C. E., and Gregory, M. E., The Current and Future Use of Telemedicine in Infectious Diseases Practice. Curr Infect Dis Rep 21(11):41, 2019.

73. Gagnon, M. P., Desmartis, M., Labrecque, M., Car, J., Pagliari, C., Pluye, P., Frémont, P., Gagnon, J., Tremblay, N., and Légaré, F., Systematic review of factors influencing the adoption of information and communication technologies by healthcare professionals. $J$ Med Syst 36:241-277, 2012.

74. Ross, J., Stevenson, F., Lau, R., and Murray, E., Factors that influence the implementation of e-health: a systematic review of systematic reviews (an update). Implement Sci 11:146, 2016.

75. Humphreys, J., Schoenherr, L., Elia, G., Saks, N. T., Brown, C., Barbour, S., and Pantilat, S. Z., Rapid Implementation of Inpatient Telepalliative Medicine Consultations During COVID-19 Pandemic. J Pain Symptom Manage 60(1):e54-e59, 2020.

76. Kim, J. Y., and Lee, K. I., Advantages and Necessities of Telehealth Care Service. Korean J Med 95(4):217-227, 2020.

77. Bashshur, R.L., On the definition and evaluation of telemedicine. Telemed J 1(1):19-30, 1995.

78. Gilbert, F., How to minimize the risk of disclosure of patient information used in telemedicine. Telemedicine J 1(2):91-94, 1995.

79. Granade, P. F., Malpractice issues in the practice of telemedicine. Telemed J 1(2):87-89, 1995. 
80. Grigsby, J., and Sanders, J. H., Telemedicine: Where it is and where it's going? Ann Intern Med 129(2):123-127, 1998.

81. Shannon, G. W., The Atlantic Rim telemedicine summit. Telemed $J$ 3(4):269-296, 1997.

82. Puskin, D. S., Opportunities and challenges to telemedicine in rural areas. J Med Syst 19(1): 59-67, 1995.

83. Korea Ministry of Health and Welfare. Temporary allowance of telephone consultation/prescription and proxy prescription. http:// www.mohw.go.kr/react/al/sal0101vw.jsp?PAR_MENU_ID= 04\&MENU_ID $=040102 \&$ CONT_SEQ $=353269$ Accessed September 12, 2020.

84. Kim, H. S., Lessons from Temporary Telemedicine Initiated owing to Outbreak of COVID-19. Healthc Inform Res 26(2):159-161, 2020.

85. U.S. Department of Health \& Human Services. FAQs on Telehealth and HIPAA during the COVID-19 nationwide. https://www.hhs. gov/sites/default/files/telehealth-faqs-508.pdf Accessed September 12, 2020.
86. The guardian. GPs told to switch to digital consultations to combat COVID-19. https://www.theguardian.com/world/2020/mar/06/ gps-told-to-switch-to-remote-consultations-to-combat-covid-19 Accessed September 12, 2020.

87. Webster, P., Virtual health care in the era of COVID-19. Lancet 395(10231):1180-1181, 2020.

88. Ministry of Health, Labour and Welfare. Online treatment based on the spread of the new coronavirus infection. https://www.mhlw.go. jp/stf/seisakunitsuite/bunya/kenkou_iryou/iryou/rinsyo/index 00014.html Accessed September 12, 2020.

89. Park, H. S., Kim, K. I., Soh, J. Y., Hyun, Y. H., Jang, S. K., Lee, S., Hwang, G. Y., and Kim, H. S., Factors Influencing Acceptance of Personal Health Record Apps for Workplace Health Promotion: Cross-Sectional Questionnaire Study. JMIR Mhealth Uhealth 8(6):e16723, 2020.

Publisher's Note Springer Nature remains neutral with regard to jurisdictional claims in published maps and institutional affiliations. 